\title{
Homens transexuais e o acesso aos serviços de saúde: revisão integrativa
}

\author{
Transsexual men and access to health services: integrative review \\ Hombres transexuales y accesso a servicios de salud: revisión integrativa
}

Recebido: 15/01/2021 | Revisado: 23/01/2021 | Aceito: 26/01/2021 | Publicado: 02/02/2021

\author{
Mariana dos Santos Gomes \\ ORCID: https://orcid.org/0000-0002-6127-9215 \\ Universidade Federal do Estado do Rio de Janeiro, Brasil \\ E-mail: marianadsg98@gmail.com \\ Francisco Jean Gomes de Sousa \\ ORCID: https://orcid.org/0000-0003-4380-2911 \\ Universidade Federal do Estado do Rio de Janeiro, Brasil \\ E-mail: jeangomesips3@gmail.com \\ Fabiana Albino Fraga \\ ORCID: https://orcid.org/0000-0002-4625-1679 \\ Universidade Federal do Estado do Rio de Janeiro, Brasil \\ E-mail: fabiana_albino2014@ @otmail.com \\ Cláudia Regina Ribeiro \\ ORCID: https://orcid.org/0000-0002-0262-0073 \\ Universidade Federal Fluminense, Brasil \\ E-mail: 13cribeiro@mail.com \\ Adriana Lemos \\ ORCID: https://orcid.org/0000-0001-9705-6200 \\ Universidade Federal do Estado do Rio de Janeiro, Brasil \\ E-mail: adrianalemos@unirio.br
}

\begin{abstract}
Resumo
Um homem transexual é um indivíduo que se percebe como homem, se identifica com os atributos socioculturalmente aceitos como masculinos, porém, nasceu com genitália feminina e foi inicialmente socializado a partir das normas impostas às mulheres. Sabe-se que essas pessoas sofrem cotidianamente com o preconceito advindo de vários âmbitos da sociedade, sendo um deles o da saúde. Desse modo, é preciso entender o atual cenário vivenciado por homens trans na saúde, para que, a partir disso, consiga-se traçar estratégias capazes de melhorar o atendimento. Este estudo tem o objetivo de identificar e analisar a produção científica nacional sobre o acesso aos serviços de saúde de homens transexuais e o papel da enfermagem durante o atendimento a essa população. Trata-se de uma revisão integrativa de literatura. A partir das buscas nas bases de dados, foram encontrados 538 estudos no total, sendo 18 pré-selecionados para avaliação e leitura do conteúdo completo e 12 selecionados para análise. Tendo a análise desses artigos como base, tornou-se claro os principais desafios encontrados durante o acesso aos serviços de saúde por homens trans. A exemplo disso, tem-se: atitudes discriminatórias, como o desrespeito relacionado ao uso do nome social; a patologização da transexualidade; despreparo profissional frente às demandas e especificidades desse grupo; o desconhecimento de alguns temas, que só são colocados em pauta, levando em conta aspectos cisheteronormativos; entre outros.
\end{abstract}

Palavras-chave: Saúde; Enfermagem; Transexualidade; Minorias sexuais e de gênero; Acesso aos serviços de saúde; Pessoas Transgênero.

\begin{abstract}
A transsexual man is an individual who perceives himself as a man, identifies himself with the sociocultural attributes accepted as masculine, however, he was born with female genitalia and was initially socialized based on the norms imposed on women. It is known that these people suffer daily from prejudice coming from various spheres of society, one of them being the health field. Thus, it is necessary to understand the current scenario experienced by trans men in health, so that from that, it is possible to outline strategies capable of improving care. This study aims to identify and analyze the national scientific production on access to health services for transsexual men and the role of nursing during the care of this population. It is an integrative literature review. From the searches in the databases, 538 studies were found in total, 18 of which were pre-selected for evaluation and reading of the complete content and 12 selected for analysis. Based on the analysis of these articles, the main challenges encountered during access to health services by trans men became clear. As an example, there are: discriminatory attitudes, such as disrespect related to the use of the social name; the pathologization of transsexuality; professional unpreparedness related the demands and specificities of this group; the ignorance of some themes, which are only placed on the agenda, considering cisheteronormative aspects; among others.
\end{abstract}


Keywords: Health; Nursing; Transsexualism; Sexual and gender minorities; Health services accessibility; Transgender persons.

\begin{abstract}
Resumen
Un hombre transexual es un individuo que se percibe a sí mismo como hombre, se identifica con los atributos socioculturales aceptados como masculinos, sin embargo, nació con genitales femeninos y se socializó inicialmente en base a las normas impuestas a las mujeres. Se sabe que estas personas sufren a diario los prejuicios derivados de diversos ámbitos de la sociedad, siendo uno de ellos el ámbito de la salud. Así, es necesario comprender el escenario actual que viven los hombres trans en salud, para que, a partir de eso, sea posible delinear estrategias capaces de mejorar el servicio. Este estudio tiene como objetivo identificar y analizar la producción científica nacional sobre el acceso a los servicios de salud para hombres transexuales y el papel de la enfermería en el cuidado de esta población. Es una revisión integradora de la literatura. De las búsquedas en las bases de datos se encontraron 538 estudios en total, 18 de los cuales fueron preseleccionados para evaluación y lectura del contenido completo y 12 seleccionados para análisis. A partir del análisis de estos artículos, se evidenciaron los principales desafíos encontrados durante el acceso a los servicios de salud por parte de los hombres trans. Como ejemplo, existen: actitudes discriminatorias, como la falta de respeto relacionada con el uso del nombre social; la patologización de la transexualidad; falta de preparación profesional ante las exigencias y especificidades de este grupo; el desconocimiento de algunos temas, que solo se colocan en la agenda, teniendo en cuenta aspectos cisheteronormativos; entre otros.

Palabras clave: Salud; Enfermería; Transexualidad; Minorías sexuales y de género; Accesibilidad a los servicios de salud; Personas transgénero.
\end{abstract}

\title{
1. Introdução
}

A transexualidade é entendida por Berenice Bento (2008) como a identidade de gênero das pessoas que não se identificam com as características socialmente designadas ao gênero que lhe foi determinado ao nascimento a partir da genitália. Assim, um homem transexual é um indivíduo que se percebe como homem, se identifica com os atributos socioculturalmente aceitos como masculinos, porém, nasceu com genitália feminina e foi inicialmente socializado a partir das normas impostas às mulheres. É importante lembrar que identidade de gênero e orientação sexual são aspectos distintos (Brasil, 2016), não havendo, portanto, relação direta entre transexualidade-homossexualidade e cisgeneridadeheterossexualidade, como se pode crer.

O direito à saúde no Brasil foi garantido na Constituição Federal como sendo fundamental, um direito de todos e um dever do Estado (Brasil, 1988). Com relação ao direito à saúde da população transexual, dois avanços dos últimos anos merecem destaque: o Processo Transexualizador (PtTr), instituído pelas Portarias $\mathrm{n}^{\mathrm{o}} 1.707$ e $\mathrm{n}^{\mathrm{o}} 457$ de agosto de 2008 e ampliado pela Portaria no 2.803, de 19 de novembro de 2013; e a Política Nacional de Saúde Integral de Lésbicas, Gays, Bissexuais, Travestis e Transexuais (LGBT). O processo transexualizador compreende um conjunto de ações voltadas a modificações corporais, como a hormonização e as cirurgias de redesignação sexual, além de acompanhamento psicológico ou psiquiátrico, acolhimento e acesso adequado aos serviços de saúde (Brasil, 2008a, 2008b, 2013a). É importante ressaltar que apenas em 2013, com a ampliação do Processo Transexualizador, os homens trans passaram a ter direito a esses mesmos serviços (Brasil, 2013a).

Com relação à Política Nacional de Saúde Integral de Lésbicas, Gays, Bissexuais, Travestis e Transexuais (LGBT), deve-se dizer que sua importância reside no reconhecimento dos "efeitos da discriminação e da exclusão no processo de saúdedoença da população LGBT" (Brasil, 2013b, p. 08), tendo por finalidade reduzir o preconceito institucional, as desigualdades de acesso aos serviços e a defesa da integralidade e da equidade no SUS como direitos dessa população (Brasil, 2013b). Considerado um grupo vulnerável, este tende a ficar a mercê da marginalização, exclusão, violência, prostituição, trabalhos informais, baixa escolaridade, menor renda per capita, aspectos que impactam de forma importante a saúde e o adoecimento. Dessa forma, a política considera o conceito ampliado de saúde e os aspectos biopsicossociais, uma vez que estes afetam a vida desses indivíduos e interferem na determinação de si (Arán et al., 2009).

Sabe-se que a população trans sofre demasiados preconceitos e que é estigmatizada na sociedade. Esses fatores estão 
presentes também no âmbito da saúde e fazem com que haja uma falta de acolhimento para com esse usuário, que se sente desrespeitado. Isso pode culminar em um afastamento dos serviços de saúde ou na busca por atendimento em serviços clandestinos, o que aumenta os riscos de adoecimento dessa população e, consequentemente, torna-a ainda mais vulnerável (Oliveira, Nogueira, Costa, Medeiros et al., 2018). Isso aponta para a necessidade de ampliar o uso de tecnologias leves (Merhy et al., 1997) no cuidado com essa população, o que para Coelho e Jorge (2009, p. 1524) "perpassa os processos de acolhimento, vínculo e atenção integral como gerenciadores das ações de saúde".

A transmasculinidade - assim como a cismasculinidade - é plural, sendo atravessada por fatores como escolaridade, posição social, cor da pele, orientação sexual entre outros aspectos que marcam as identidades e que impactam as formas como são acolhidos e tratados nos serviços de saúde. É importante dizer ainda que, como aponta Almeida (2012), ser um homem trans não significa necessariamente passar por modificações corporais através de cirurgias ou da hormonização, pois as identidades de gênero não estão condicionadas ao corpo normativo.

Nos últimos anos, os movimentos LGBTQIA+ ganharam relevância e têm apontado a negação do direito à saúde imposto à essa população. As causas são muitas, algumas já citadas, mas a falta de preparo dos profissionais de saúde e a ausência de interesse sobre o assunto, que invisibiliza essa população nos próprios serviços, têm sido apontadas como fatores relevantes, sendo um desrespeito à própria legislação vigente. Dessa forma, o profissional enfermeiro pode desempenhar um importante papel durante as consultas de enfermagem, em qualquer nível de atenção.

Este estudo justifica-se pela necessidade de conhecer como tem se dado o acesso aos serviços de saúde pelos homens trans, as dificuldades que têm encontrado e suas necessidades de saúde, para que se consiga traçar e difundir estratégias que melhorem esse atendimento. Além disso, tem-se o intuito de contribuir para a difusão de conhecimento e dar mais visibilidade às ações da enfermagem junto à população trans e, especialmente, aos homens trans, pois é sabido que a área ainda carece de trabalhos científicos que tragam subsídios para a promoção de saúde desses homens, ampliando a consciência política, profissional e social. Neste sentido, este estudo objetiva identificar e analisar a produção científica nacional sobre o acesso aos serviços de saúde de homens transexuais e o papel da enfermagem durante o atendimento a essa população.

\section{Metodologia}

Trata-se de uma revisão integrativa de literatura. A escolha pela revisão integrativa justifica-se por ser "a mais ampla abordagem referente às revisões, permitindo a inclusão de estudos experimentais e não experimentais", com a finalidade de entender o tema estudado de forma mais ampla e sólida, a partir de diversas perspectivas e diferentes formas de abordagem (Souza et al., 2010, p. 103). Além disso, esse tipo de metodologia permite que o conhecimento já produzido sobre um determinado assunto seja novamente explorado, através de análises e junção de opiniões, por exemplo (Botelho et al., 2011).

Para o desenvolvimento desta pesquisa, optou-se por seguir as etapas propostas por Botelho, Cunha e Macedo (2011, p. 129), os quais destacam que "o processo de revisão integrativa deve seguir uma sucessão de etapas bem definidas". As etapas por eles definidas são:

1) Identificação do tema e seleção da questão da pesquisa; 2) Estabelecimento de critérios de inclusão e exclusão; 3) Identificação dos estudos pré-selecionados e selecionados; 4) Categorização dos estudos selecionados; 5) Análise e interpretação dos resultados; 6) Apresentação da revisão/síntese do conhecimento.

Na primeira etapa da revisão integrativa foi elaborada a pergunta de pesquisa conforme a estratégia de busca, a partir disso utilizou-se o acrônimo PICO ou PICo, onde P = Population (população), C = Concept or Phenomenon of Interest (Conceito ou fenômeno de Interesse) e C $=$ Context (contexto). A partir disso, levantou-se a seguinte questão norteadora: 
"Como se dá o acesso aos serviços de saúde de homens transexuais no Brasil?"

Nesta pesquisa, a busca dos estudos científicos primários foi desenvolvida em importantes bases de dados da área da saúde: LILACS (Literatura Latino-Americana e do Caribe em Ciências da Saúde), BDENF (Bases de Dados em Enfermagem), MEDLINE (Sistema Online de Busca e Análise de Literatura Médica) e SCIELO (ScientificElectronic Library Online). Os descritores utilizados para a busca nas bases de dados, conforme a plataforma de Descritores em Ciências da Saúde (DECS) foram: Pessoas Transgênero, Transexualismo, Minorias Sexuais e de Gênero, Acesso aos Serviços de Saúde, Enfermagem. Durante o levantamento de dados, os descritores foram articulados da seguinte forma: "Acesso aos Serviços de Saúde" AND "Pessoas Transgênero", "Acesso aos Serviços de Saúde" AND "Transexualismo" e "Acesso aos Serviços de Saúde" AND "Minorias Sexuais e de Gênero".

$\mathrm{Na}$ segunda etapa, foram traçados os seguintes critérios de inclusão: artigos científicos que retratassem a realidade brasileira no acesso aos serviços de saúde aos homens transexuais, redigidos nos idiomas português, inglês ou espanhol. E como critérios de exclusão: artigos científicos não disponíveis com conteúdo na íntegra; revisões integrativas, teses, dissertações, protocolos ou manuais. Para captar o máximo de artigos científicos, optou-se por não fazer recorte temporal.

Na terceira etapa, após a aplicação dos critérios de inclusão e exclusão, foi realizada a identificação dos artigos préselecionados, a partir da leitura do título, resumo, objetivos e resultados na própria base de dados. O nível de evidência dos artigos foi verificado conforme os critérios de Souza, Silva e Carvalho (2010, p. 104-105), apresentados logo abaixo:

- $\quad$ Nível 1: evidências resultantes da meta-análise de múltiplos estudos clínicos controlados e randomizados;

- $\quad$ Nível 2: evidências obtidas em estudos individuais com delineamento experimental;

- $\quad$ Nível 3: evidências de estudos quase experimentais;

- $\quad$ Nível 4: evidências de estudos descritivos (não experimentais) ou com abordagem qualitativa;

- $\quad$ Nível 5: evidências provenientes de relatos de caso ou de experiência;

- $\quad$ Nível 6: evidências baseadas em opiniões de especialistas.

A partir disso, na quarta etapa realizou-se a categorização e análise dos estudos selecionados. Ademais, na quinta etapa, apresentou-se a interpretação dos resultados e, por fim, na sexta e última etapa, realizou-se a síntese do conhecimento produzido com propostas para estudos futuros. Cabe destacar que a etapa 3 foi realizada separadamente por dois autores.

\section{Resultados}

Primeiramente, no início da pesquisa, em 2019, as buscas foram realizadas com os descritores "Acesso aos Serviços de Saúde", "Pessoas Transgênero", "Transexualismo", "Minorias Sexuais e de Gênero" e "Enfermagem", mesclando-os da seguinte forma: "Acesso aos Serviços de Saúde" AND "Pessoas Transgênero" AND "Enfermagem", "Acesso aos Serviços de Saúde" AND "Transexualismo" AND "Enfermagem" e "Acesso aos Serviços de Saúde" AND "Minorias Sexuais e de Gênero" AND "Enfermagem". Porém, não foi encontrado nenhum resultado nas bases de dados anteriormente citadas.

Em 2020, as buscas foram refeitas com o intuito de atualizar os dados anteriormente obtidos. Desse modo, ao utilizar o descritor "Enfermagem" foram encontrados 2 artigos, levando em conta os critérios de inclusão e exclusão. Portanto, devido ao pequeno número de estudos disponíveis, optou-se por focar nos resultados encontrados sem utilizar o descritor "Enfermagem" nas buscas. Ademais, é importante ressaltar que os artigos encontrados através da busca utilizando o descritor citado, foram encontrados mesmo sem o uso dele, através da combinação de descritores já citada na metodologia desse estudo.

Após a varredura nas bases de dados, foram identificados 538 estudos no total, e após a leitura de títulos e resumos, 18 foram pré-selecionados para leitura do conteúdo na íntegra. Destes registros, 12 artigos foram selecionados para análise, 
sendo alguns encontrados em apenas uma das bases de dados citadas e outros sendo encontrados em mais de uma delas. O processo de elegibilidade e inclusão pode ser visualizado no fluxograma abaixo, denominado PRISMA (Principais Itens para Relatar Revisões sistemáticas e Meta-análises), conforme a Figura 1.

Figura 1. Fluxograma da condução e etapas do estudo segundo o PRISMA.

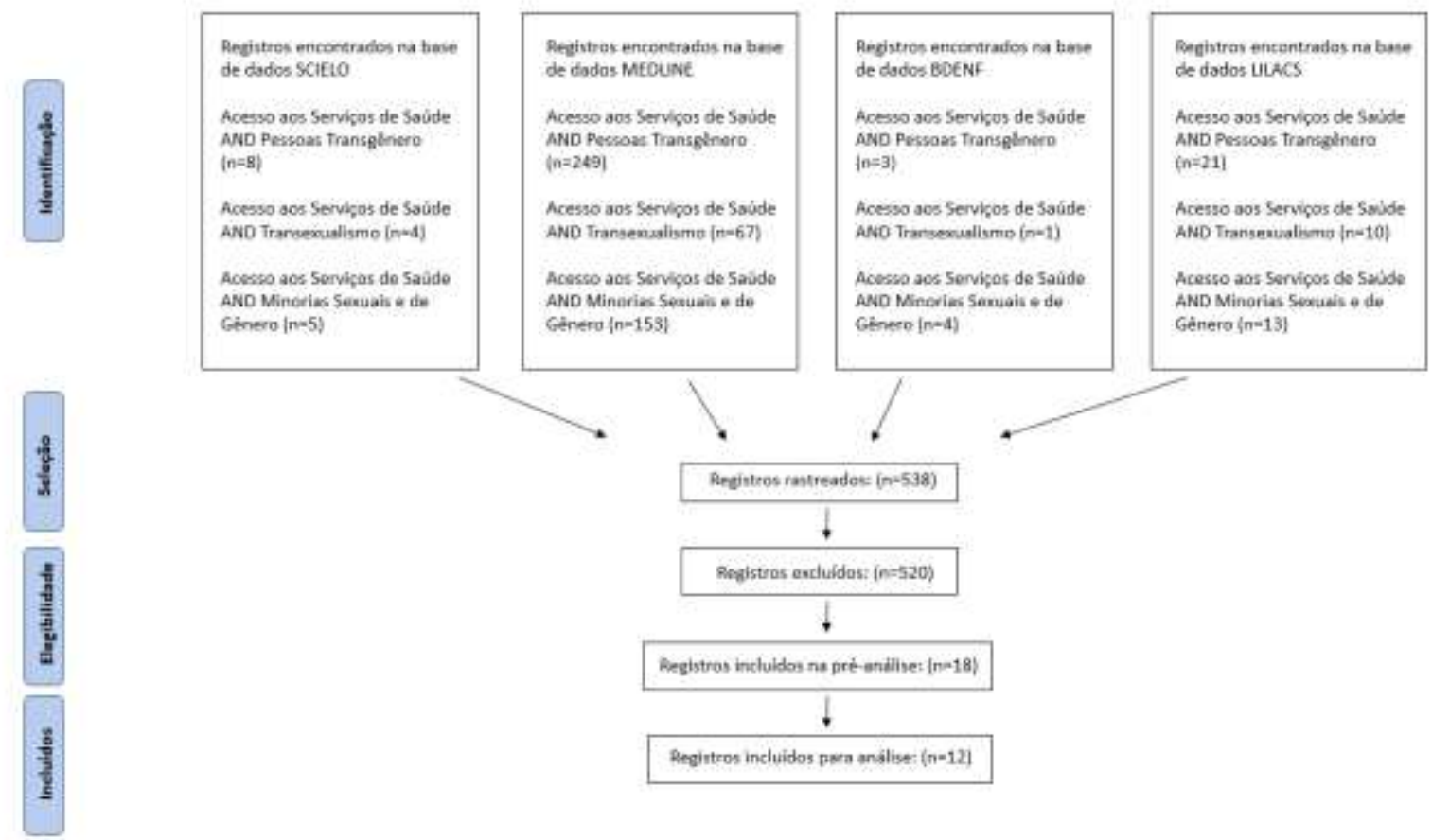

Fonte: Autores.

O fluxograma acima demonstra de forma resumida, a maneira com a qual as pesquisas foram feitas a partir dos descritores e operadores boleanos e a quantidade de artigos encontrados diante de cada combinação realizada. Assim como, o número de estudos incluídos ou excluídos em cada etapa da pesquisa.

Após as buscas nas bases de dados SCIELO, MEDLINE, BDENF e LILACS foram selecionados 12 artigos para análise, a tabela abaixo traz algumas informações sobre eles.

Tabela 1. Artigos selecionados para análise.

\begin{tabular}{|c|c|c|c|c|c|c|}
\hline Título & Ano & Objetivo & Local & Método & $\begin{array}{c}\text { Instrumentos } \\
\text { utilizados }\end{array}$ & $\begin{array}{c}\text { Nível de } \\
\text { Evidência }\end{array}$ \\
\hline $\begin{array}{c}\text { Vidas que } \\
\text { esperam? } \\
\text { Itinerários do } \\
\text { acesso a } \\
\text { serviços de } \\
\text { saúde para } \\
\text { homens trans } \\
\text { no Brasil e na } \\
\text { Argentina. }\end{array}$ & 2019 & $\begin{array}{l}\text { O texto, fruto de pesquisa } \\
\text { antropológica nas regiões } \\
\text { metropolitanas de Goiânia e } \\
\text { de Buenos Aires, visa a } \\
\text { contribuir para as discussões } \\
\text { em torno do acesso à saúde } \\
\text { para homens trans nesses } \\
\text { dois contextos, buscando } \\
\text { apontar para as } \\
\text { ambivalências relacionadas } \\
\text { a seus itinerários } \\
\text { terapêuticos em busca de }\end{array}$ & $\begin{array}{c}\text { Goiás, } \\
\text { Brasil e } \\
\text { Buenos } \\
\text { Aires, } \\
\text { Argentina. }\end{array}$ & $\begin{array}{l}\text { Pesquisa de } \\
\text { abordagem } \\
\text { qualitativa. }\end{array}$ & Entrevistas. & 4 \\
\hline
\end{tabular}




\begin{tabular}{|c|c|c|c|c|c|c|}
\hline & & cuidados biomédicos. & & & & \\
\hline $\begin{array}{l}\text { Dificuldades } \\
\text { vividas por } \\
\text { pessoas trans } \\
\text { no acesso ao } \\
\text { Sistema Único } \\
\text { de Saúde. }\end{array}$ & 2016 & $\begin{array}{l}\text { Objetivou-se discutir as } \\
\text { dificuldades de pessoas } \\
\text { trans moradoras da região } \\
\text { metropolitana da Grande } \\
\text { Vitória/ES em acessarem os } \\
\text { serviços de saúde no SUS. }\end{array}$ & $\begin{array}{l}\text { Espírito } \\
\text { Santo. }\end{array}$ & $\begin{array}{l}\text { Pesquisa de } \\
\text { abordagem } \\
\text { qualitativa. }\end{array}$ & $\begin{array}{c}\text { Entrevistas } \\
\text { semiestruturadas } \\
\text {, gravadas em } \\
\text { áudio digital, } \\
\text { orientadas por } \\
\text { um questionário } \\
\text { e diário de } \\
\text { campo. }\end{array}$ & 4 \\
\hline $\begin{array}{c}\text { A Política } \\
\text { Nacional de } \\
\text { Saúde Integral } \\
\text { de Lésbicas, } \\
\text { Gays, } \\
\text { Bissexuais e } \\
\text { Transgêneros } \\
\text { (LGBT) e o } \\
\text { acesso ao } \\
\text { Processo } \\
\text { Transexualizad } \\
\text { or no Sistema } \\
\text { Único de Saúde } \\
\text { (SUS): avanços } \\
\text { e desafios. }\end{array}$ & 2017 & $\begin{array}{l}\text { Objetivou analisar como o } \\
\text { Ministério da Saúde (MS) } \\
\text { vem implementando o } \\
\text { Processo Transexualizador } \\
\text { (PrTr) no SUS. }\end{array}$ & Curitiba. & $\begin{array}{l}\text { Pesquisa } \\
\text { exploratória, } \\
\text { combinando } \\
\text { métodos } \\
\text { quantitativos } \\
\text { e qualitativos. }\end{array}$ & $\begin{array}{c}\text { Pesquisa de } \\
\text { documentos } \\
\text { oficiais de } \\
\text { domínio } \\
\text { público, } \\
\text { sistematização } \\
\text { de dados } \\
\text { quantitativos e } \\
\text { análise das } \\
\text { memórias do } \\
\text { Comitê Técnico } \\
\text { de Saúde LGBT } \\
\text { (CTSLGBT) do } \\
\text { MS. }\end{array}$ & 4 \\
\hline $\begin{array}{c}\text { Acesso de } \\
\text { lésbicas, Gays, } \\
\text { bissexuais e } \\
\text { travestis/transe } \\
\text { xuais às } \\
\text { Unidades } \\
\text { Básicas de } \\
\text { Saúde da } \\
\text { Família. }\end{array}$ & 2018 & $\begin{array}{l}\text { Compreender o acesso de } \\
\text { lésbicas, gays, bissexuais e } \\
\text { travestis/transexuais às } \\
\text { Unidades Básicas de Saúde } \\
\text { da Família. }\end{array}$ & Paraíba. & $\begin{array}{c}\text { Pesquisa de } \\
\text { abordagem } \\
\text { qualitativa. }\end{array}$ & $\begin{array}{c}\text { Utilizou-se } \\
\text { entrevista } \\
\text { semiestruturada } \\
\text { e o teste de } \\
\text { associação livre } \\
\text { de palavras. }\end{array}$ & 4 \\
\hline $\begin{array}{l}\text { Do diagnóstico } \\
\text { de Transtorno } \\
\text { de Identidade } \\
\text { de gênero às } \\
\text { redescrições da } \\
\text { experiência da } \\
\text { transexualidade } \\
\text { : uma reflexão } \\
\text { sobre gênero, } \\
\text { tecnologia e } \\
\text { saúde. }\end{array}$ & 2009 & $\begin{array}{c}\text { Discutir os desafios para a } \\
\text { gestão de políticas públicas } \\
\text { para essa população, } \\
\text { particularmente, a } \\
\text { necessidade do diagnóstico } \\
\text { de Transtorno de Identidade } \\
\text { de Gênero como condição } \\
\text { de acesso. }\end{array}$ & $\begin{array}{l}\text { Rio de } \\
\text { Janeiro. }\end{array}$ & $\begin{array}{c}\text { Estudo } \\
\text { baseado em } \\
\text { opiniões de } \\
\text { especialistas. }\end{array}$ & $\begin{array}{c}\text { Estudo sobre as } \\
\text { práticas de } \\
\text { saúde dos } \\
\text { principais } \\
\text { serviços que } \\
\text { prestam } \\
\text { assistência a } \\
\text { usuários(as) } \\
\text { transexuais no } \\
\text { Brasil. }\end{array}$ & 6 \\
\hline $\begin{array}{c}\text { "Viver } \\
\text { dignamente": } \\
\text { necessidades e } \\
\text { demandas de } \\
\text { saúde de } \\
\text { homens trans } \\
\text { em Salvador, } \\
\text { Bahia, Brasil. }\end{array}$ & 2018 & $\begin{array}{l}\text { Discutir as necessidades e } \\
\text { demandas de saúde de } \\
\text { homens trans, tema pouco } \\
\text { estudado que, com } \\
\text { frequência, interpelando a } \\
\text { construção de práticas de } \\
\text { cuidado em saúde para esta } \\
\text { população. }\end{array}$ & Salvador. & $\begin{array}{c}\text { Pesquisa de } \\
\text { abordagem } \\
\text { qualitativa. }\end{array}$ & $\begin{array}{c}\text { Entrevistas } \\
\text { semiestruturadas }\end{array}$ & 4 \\
\hline $\begin{array}{l}\text { Psicologia e } \\
\text { políticas de }\end{array}$ & 2019 & $\begin{array}{c}\text { Este texto se propõe a } \\
\text { compor uma reflexão sobre }\end{array}$ & Rio de & $\begin{array}{c}\text { Estudo } \\
\text { baseado em }\end{array}$ & - & 6 \\
\hline
\end{tabular}




\begin{tabular}{|c|c|c|c|c|c|c|}
\hline $\begin{array}{c}\text { saúde da } \\
\text { população } \\
\text { trans: } \\
\text { encruzilhadas, } \\
\text { disputas e } \\
\text { porosidades. }\end{array}$ & & $\begin{array}{l}\text { algumas fronteiras que } \\
\text { atravessam a Psicologia } \\
\text { quando posta em contato } \\
\text { com as demandas dos } \\
\text { segmentos trans e com a } \\
\text { operacionalização de } \\
\text { políticas de saúde para este } \\
\text { segmento. }\end{array}$ & Janeiro. & $\begin{array}{c}\text { opiniões de } \\
\text { especialistas. }\end{array}$ & & \\
\hline $\begin{array}{c}\text { Discursos sobre } \\
\text { o cuidado em } \\
\text { saúde de } \\
\text { Lésbicas, Gays, } \\
\text { Bissexuais, } \\
\text { Travestis, } \\
\text { Transexuais } \\
\text { (LGBT) entre } \\
\text { médicas(os) da } \\
\text { Estratégia } \\
\text { Saúde da } \\
\text { Família. }\end{array}$ & 2019 & $\begin{array}{l}\text { Objetiva-se identificar os } \\
\text { discursos sobre o acesso e a } \\
\text { qualidade da atenção } \\
\text { integral à saúde da } \\
\text { população de Lésbicas, } \\
\text { Gays, Bissexuais, Travestis } \\
\text { e Transexuais (LGBT) entre } \\
\text { médicas(os) da Estratégia } \\
\text { Saúde da Família, refletindo } \\
\text { sobre como esses discursos } \\
\text { podem impactar o cuidado } \\
\text { em saúde da população } \\
\text { LGBT }\end{array}$ & $\begin{array}{l}\text { Uberlândia } \\
\text { e Belo } \\
\text { Horizonte. }\end{array}$ & $\begin{array}{l}\text { Pesquisa de } \\
\text { abordagem } \\
\text { qualitativa. }\end{array}$ & $\begin{array}{c}\text { Entrevistas } \\
\text { semiestruturadas }\end{array}$ & 4 \\
\hline $\begin{array}{c}\text { Body } \\
\text { construction } \\
\text { and health } \\
\text { itineraries: a } \\
\text { survey among } \\
\text { travestis and } \\
\text { trans people in } \\
\text { Rio de Janeiro, } \\
\text { Brazil. }\end{array}$ & 2019 & $\begin{array}{c}\text { O objetivo do estudo } \\
\text { consistiu em conhecer o } \\
\text { perfil sociodemográfico } \\
\text { desta população, bem como } \\
\text { compreender (i) os seus } \\
\text { mecanismos de acesso aos } \\
\text { serviços de saúde } \\
\text { disponíveis, nomeadamente } \\
\text { modificações corporais e } \\
\text { tecnologias de detecção e } \\
\text { prevenção do HIV / SIDA; e } \\
\text { (ii) o exercício de outros } \\
\text { direitos civis, especialmente } \\
\text { os que envolvem alteração } \\
\text { de nome e / ou gênero em } \\
\text { documentos oficiais. }\end{array}$ & $\begin{array}{l}\text { Rio de } \\
\text { Janeiro. }\end{array}$ & $\begin{array}{c}\text { Pesquisa de } \\
\text { abordagem } \\
\text { qualitativa. }\end{array}$ & Questionário. & 4 \\
\hline $\begin{array}{l}\text { Avaliação da } \\
\text { implementação } \\
\text { da Política } \\
\text { Nacional de } \\
\text { Saúde Integral } \\
\text { à população } \\
\text { LGBT em um } \\
\text { município da } \\
\text { região Sudeste } \\
\text { do Brasil. }\end{array}$ & 2020 & $\begin{array}{l}\text { Avaliar a implementação da } \\
\text { Política Nacional de Saúde } \\
\text { Integral à População LGBT } \\
\text { (PNAIPLGBT) na atenção } \\
\text { básica de saúde e } \\
\text { compreender o } \\
\text { conhecimento de } \\
\text { enfermeiros da Estratégia } \\
\text { Saúde da Família acerca da } \\
\text { diversidade sexual e da } \\
\text { homofobia. }\end{array}$ & $\begin{array}{l}\text { Espírito } \\
\text { Santo. }\end{array}$ & $\begin{array}{c}\text { Estudo } \\
\text { descritivo, } \\
\text { exploratório e } \\
\text { de natureza } \\
\text { qualitativa. }\end{array}$ & $\begin{array}{c}\text { Entrevista } \\
\text { semiestruturada } \\
\text { e observação } \\
\text { participante. }\end{array}$ & 4 \\
\hline $\begin{array}{c}\text { Serviços de } \\
\text { saúde para } \\
\text { lésbicas, gays, } \\
\text { bissexuais e } \\
\text { travestis/transe } \\
\text { xuais. }\end{array}$ & 2018 & $\begin{array}{c}\text { Analisar, sob a ótica de } \\
\text { profissionais da Equipe } \\
\text { Saúde da Família, o acesso } \\
\text { de Lésbicas, Gays, } \\
\text { Bissexuais e } \\
\text { Travestis/Transexuais às } \\
\text { Unidades Básicas de Saúde }\end{array}$ & Recife. & $\begin{array}{c}\text { Estudo } \\
\text { quantiqualitati } \\
\text { vo, de campo, } \\
\text { exploratório e } \\
\text { descritivo. }\end{array}$ & $\begin{array}{l}\text { Questionário } \\
\text { semiestruturado, } \\
\text { roteiro de } \\
\text { entrevista e a } \\
\text { Técnica de } \\
\text { Associação } \\
\text { Livre de }\end{array}$ & 4 \\
\hline
\end{tabular}




\begin{tabular}{|c|c|c|c|c|c|c|}
\hline & & da Família. & & & Palavras. & \\
\hline $\begin{array}{c}\text { Healthcare } \\
\text { Needs of and } \\
\text { Access Barriers } \\
\text { for Brazilian } \\
\text { Transgender } \\
\text { and Gender } \\
\text { Diverse People. }\end{array}$ & 2016 & $\begin{array}{l}\text { O objetivo deste estudo foi } \\
\text { avaliar as necessidades de } \\
\text { saúde e as barreiras de } \\
\text { acesso à TGD em dois } \\
\text { estados brasileiros que } \\
\text { oferecem atendimento } \\
\text { específico a essa população. }\end{array}$ & $\begin{array}{c}\text { Rio Grande } \\
\text { do Sul e São } \\
\text { Paulo. }\end{array}$ & $\begin{array}{c}\text { Pesquisa de } \\
\text { abordagem } \\
\text { qualitativa e } \\
\text { quantitativa. }\end{array}$ & Questionário. & 4 \\
\hline
\end{tabular}

Fonte: Autores.

A tabela acima evidencia algumas informações importantes. É demonstrado, por exemplo, que o principal instrumento de construção de dados utilizado nos estudos foi a entrevista, além do nível de evidência de cada um dos artigos e o local onde os estudos foram realizados. Aqui é importante salientar que um dos artigos tratava de pesquisa realizada no Brasil e Argentina, no entanto, para a analise dos dados desta pesquisa, consideramos apenas os que se referem ao Brasil. Também é mostrado acima o período de publicação dos artigos, que foi de 2009 a 2020.

Questões sobre o ciclo gravídico-puerperal de homens trans não foram apontadas por nenhum dos artigos. Outrossim, a assistência de enfermagem foi pouco tratada nesses estudos, sendo apresentada em apenas dois deles, trazendo a perspectiva profissional relacionada ao cuidado.

A partir da leitura do material, identificou-se temas comuns, que foram agrupados nas seguintes categorias: diferentes formas com as quais padrões socialmente impostos e naturalizados influenciam na saúde de homens trans; transfobia; patologização da transexualidade; como é realizado o Processo Transexualizador; dificuldades para obtenção de um atendimento adequado e demora no acesso aos serviços; e questões relacionadas à automedicação.

\section{Discussão}

A cisheteronormatividade é uma concepção que considera como normal ser cisgênero e heterossexual, considerando como divergente, errado e/ou doente tudo e todos que fogem desse padrão (Popadiuk et al., 2017; Rocon et al., 2016; Souza \& Iriart, 2018). Isso faz com que essa população, por não seguir essa lógica, sofra preconceito e discriminação e que seus direitos sejam deslegitimados e desrespeitados. Além disso, há carência de serviços de saúde voltados para essa parcela populacional, fazendo com que as pessoas transexuais e travestis sejam o grupo que mais encontra adversidades relacionadas a políticas e serviços de saúde, sejam eles específicos ou não (Mello et al., 2011).

Levando em consideração o campo da saúde, atitudes preconceituosas fazem-se presentes através de olhares, risadas, comentários, frases e atitudes. Somado a transfobia, pode-se citar também a questão do desrespeito relacionado ao uso do nome social, que mesmo sendo um direito garantido para toda a população desde 2009 pela Carta de Direitos dos Usuários do SUS (Brasil, 2016), não é algo respeitado na prática profissional (Rocon et al., 2016). Vale destacar que esse direito está explícito e de modo especial para a população trans através da Nota Técnica nº 18/2014 (Brasil, 2014).

Há ainda questões subjetivas que perpassam ideologias culturais e crenças, as quais ainda fazem-se muito presentes nos serviços de saúde (Pereira \& Chazan, 2019) e que reforçam esse cenário de preconceito e discriminação contra pessoas trans. Esse tipo de comportamento por parte dos profissionais de saúde faz com que os usuários se afastem dos serviços, fazendo com que esse indivíduo busque atendimentos apenas para medidas curativas, deixando de lado ações de prevenção (Oliveira, Nogueira, Costa, Medeiros et al., 2018). Além disso, há aqueles que optam por omitirem sua identidade de gênero, com o objetivo de não sofrer preconceito e as consequências que o mesmo acarreta para a saúde, seja ela física ou mental (Oliveira, Nogueira, Costa, Silva et al., 2018). 
Em 2018, a Organização Mundial de Saúde (OMS) anunciou que a transexualidade seria realocada na $11^{\text {a }}$ Classificação Internacional de Doenças (CID), a qual entrará em vigor em 2022. A questão que antes era designada como um transtorno mental, agora integra a categoria de condições relacionadas à saúde sexual, sendo caracterizada como Incongruência de Gênero (Vieira et al., 2019). Esse acontecimento é de extrema importância para auxiliar na despatologização dessas identidades.

Em contrapartida, ainda há ações na prática profissional, que retomam a patologização. A exemplo disso têm-se a exigência de laudos e diagnósticos e a necessidade de avaliação multiprofissional para se iniciar os cuidados no âmbito do Processo Transexualizador (Brasil, 2008a, 2013a). Segundo Vieira et al. (2019, p. 167) "a lógica patologizante desconsidera a autonomia de pessoas trans a respeito de seu próprio corpo e sua própria vida", colocando o profissional de saúde, especificamente o psiquiatra, como responsável por estabelecer a veracidade dessa identidade de gênero. Outrossim, para Geisler, Reis e Sperlin (2013), a patologização da transexualidade leva em conta a genitália do indivíduo para determinar sua identidade de gênero. Isso faz com que as pessoas trans sintam-se obrigadas a encaixar-se em moldes cisnormativos para conseguir adentrar nos serviços (Vieira et al., 2019).

O cuidado da população trans de uma forma geral é estruturado pelos componentes da Atenção Básica e pela Atenção Especializada. A Atenção Básica "é o componente da rede responsável pela coordenação do cuidado e por realizar a atenção contínua da população, [...] além de ser porta de entrada prioritária do usuário na rede" (Brasil, 2013a). Já a Atenção Especializada "é um conjunto de diversos pontos de atenção com diferentes densidades tecnológicas" (Brasil, 2013a). Os componentes da Atenção Especializada no PrTr incluem as modalidades de atenção ambulatorial (acompanhamento clínico, pré e pós-operatório e hormonização) e hospitalar (realização de cirurgias e acompanhamento pré e pós-operatório) (Brasil, 2013a).

A pessoa que desejar adentrar ao Processo Transexualizador deve seguir um percurso definido pelas Portarias que regulamentam o mesmo. Nesse contexto, sabe-se que é preciso passar primeiramente pela Atenção Básica para conseguir chegar à Atenção Especializada (Brasil 2013a), porém, há alguns obstáculos nesse caminho. Isso faz com que o atendimento não seja realizado de forma integral, focando apenas na construção do corpo, ou seja nos procedimentos relacionados ao Processo Transexualizador (Ahmad et al., 2020). Os dois níveis de atenção citados trazem adversidades para os homens trans. $\mathrm{Na}$ Atenção Básica, o problema mais mencionado em estudos é a dificuldade de acesso devido ao preconceito ali presente (Oliveira, Nogueira, Costa, Medeiros et al., 2018) e "à falta de sensibilização e sigilo ético dos trabalhadores da Unidade Básica de Saúde" (Oliveira, Nogueira, Costa, Silva et al., 2018). Sendo assim, os homens trans são encontrados, na maior parte das vezes, em serviços especializados (Guimarães et al., 2020), por se sentirem mais acolhidos e para evitar episódios de preconceito, constrangimento e falta de respeito ao nome social. Por este motivo, esses indivíduos acabam tendo dificuldade ou até não conseguindo acessar o primeiro nível de atenção, o que os auxiliaria a seguir o fluxo ideal de atendimento para os demais níveis, tendo assim, atendimento especializado acompanhado e de forma orientada (Solka \& Antoni, 2020).

Além disso, no cenário da Atenção Especializada, contratempos também são observados. Os indivíduos relatam dificuldade no agendamento das cirurgias (Arán \& Murta, 2009) e poucas cidades onde há hospitais habilitados a realizarem o Processo Transexualizador, o que faz com que as cirurgias sejam realizadas em clínicas privadas (Souza \& Iriart, 2018). Ademais, cita-se também o pequeno número de profissionais especializados no assunto, seja na rede privada ou pública, o que deixa claro, que ter recursos financeiros não garante nem o acesso aos serviços (Braz, 2019); e a dificuldade na obtenção de hormônios (Carrara et al., 2019), pois a testosterona só é vendida com receita médica controlada. Essas intercorrências fazem com que o usuário procure outras formas de conseguir os serviços ou que, até mesmo, se afaste dos mesmos.

Por outro lado, Paulino, Rasera e Teixeira (2019) chamam a atenção para o que nominaram de "discurso da não diferença", o que, segundo eles, seria uma forma dos profissionais minimizarem o preconceito de que são acusados afirmando 
que as necessidades da população LGBT são as mesmas dos demais indivíduos, desconsiderando as demandas específicas desse grupo. É preciso lembrar que o cuidado deve ser universal, integral e equânime, independente se a demanda é específica ou não, ou seja, o usuário deve ter um atendimento adequado e respeitoso ao procurar auxílio para uma dor de cabeça ou se quiser orientação sobre como iniciar a hormonização, por exemplo. Porém, ao utilizar o discurso que essa parcela social não tem especificidades, invisibiliza-se as demandas e as necessidades dessas pessoas, as quais já são mascaradas pelos estigmas associados a elas. Isso é reflexo de um despreparo profissional e da pouca vontade de saber mais sobre essa população (Guimarães et al., 2020; Paulino et al., 2019), o que gera um atendimento inadequado, deficitário e desrespeitoso para com o usuário.

A automedicação é um assunto que demanda muita atenção, devido aos riscos relacionados a mesma e a seu alto índice de realização (Arán \& Murta, 2009; Souza \& Iriart, 2018). Dentre as principais causas relacionadas a esse tópico estão a dificuldade de se chegar à Atenção Especializada, devido às adversidades encontradas na Atenção Básica e à demora nesse percurso (Atenção Básica -> Atenção Especializada); necessidade de receita médica para obtenção do hormônio masculinizante; dificuldade de encontrar o medicamento em farmácias e instituições de saúde (Braz, 2019; Carrara et al., 2019). Por isso, os homens trans buscam formas mais fáceis de obter a testosterona, que será ministrada sem o acompanhamento qualificado, podendo acarretar problemas de saúde e até a morte.

Vale destacar, ainda, que em nenhum dos artigos selecionados falava-se sobre a demanda de serviços de pré-natal e/ou gestação de homens trans, temas pouco estudados, quase nunca discutidos e raramente conhecidos. Isso evidencia a cisnormatividade do sistema de saúde, pois assuntos relacionados ao ciclo gravídico-puerperal são, exclusivamente, pesquisados e estudados levando em consideração a mulher cis e suas necessidades. Portanto, torna-se essencial que o tema seja mais estudado, para que consiga-se entender como se dá a gestação no corpo de homem trans; como a hormonização, feita por alguns, pode interferir no engravidamento e na gestação; a possibilidade de amamentar se tiver feito mastectomia total; quanto tempo depois pode-se retomar a ingestão de hormônios, entre outras dúvidas. Isso, na tentativa de proporcionar um atendimento o mais adequado e acolhedor possível num momento tão delicado e que gera tantas dúvidas, sentimentos e receios.

A assistência de enfermagem foi pouco encontrada nos estudos. No que diz respeito ao Código de Ética da Enfermagem, ainda há uma séria contradição, pois, embora alguns avanços tenham se apresentado nos últimos anos, essas normativas ainda não foram integralmente acolhidas no cotidiano de trabalho dos profissionais da saúde, impedindo a garantia do acesso universal à saúde por homens trans. Além disso, é apontado por Moscheta e Santos (2010, p. 155) que "os serviços de saúde tendem a se organizar para uma clientela heterossexual, limitando suas possibilidades de atuação efetiva junto a pacientes LGBTs".

Portanto, como limitadores, apontam-se poucos estudos sobre a temática, principalmente nas bases de dados nacionais, além de pouco uso do descritor "Enfermagem" nos estudos, conforme a plataforma DECS. Além disso, é importante ressaltar sobre o uso do descritor "transexualismo" (sufixo "ismo" = doença), termo usado de forma pejorativa, pois,

(...) retrata o atraso da medicina nas questões de gênero e sexualidade, além de aclarar uma compreensão patologizante altamente prejudicial para o tratamento de pessoas que, em função de sua transexualidade, não estão de nenhuma forma incapacitadas ou inabilitadas, por essa razão, a exercer ou desempenhar atividades cotidianas e habituais da vida pública e privada (Oliveira, 2014).

A plataforma DECS mostrou-se desatualizada com relação à nomenclatura deste descritor em específico. Isso advém do fato do mesmo só ter sido atualizado em meados de 2020, deixando de ser "transexualismo" e passando a ser 
"transexualidade". Permaneceu-se com o uso do termo "transexualismo" para a realização das buscas, pois a pesquisa já estava em suas etapas finais e o levantamento de dados já havia sido feito e estava sendo novamente realizado. Porém, colocamos como palavra-chave do estudo o termo mais atual e correto, ou seja, "transexualidade".

\section{Considerações Finais}

Durante a elaboração deste estudo, observou-se pouca quantidade de materiais disponíveis sobre o acesso aos serviços de saúde por homens transexuais. Esse número é ainda menor quando associado ao papel da Enfermagem. Isso torna perceptível a escassez de materiais sobre o assunto e evidencia a necessidade de mais pesquisas sobre a temática.

Saúde é um direito garantido constitucionalmente. Por isso, é de suma importância, que discussões sobre o tema deste artigo sejam realizadas e que novas políticas públicas voltadas para homens trans sejam incentivadas. É fundamental também, que as políticas públicas já existentes destinadas a essa população sejam colocadas em prática e que se repense na melhor maneira para que isso aconteça; além de traçar estratégias para disseminar essas informações. Outrossim, é essencial que a universalidade, a integralidade e a equidade estejam presentes em todo atendimento de saúde, seja ele específico ou não.

Com base nas informações obtidas nos estudos, torna-se evidente que os profissionais de saúde necessitam de uma relação mais estreita com o assunto. Para isso, é necessário que a formação profissional seja revisada, para que durante a graduação, o estudante tenha mais contato com questões voltadas a população LGBTQIA+. Além disso, é preciso tornar a educação permanente mais presente nas instituições de saúde, com o propósito de trazer o assunto para aqueles que o desconhecem, porém já atuam na prática profissional. É importante que nesses dois momentos, a graduação e a atuação propriamente dita, o profissional tenha em mente que, independente, de conhecimento específico sobre algo, é crucial que haja respeito com o outro. Isso auxiliará na ampliação de saberes desses profissionais e capacitará seu atendimento, tornando-o assim, adequado, acolhedor e respeitoso.

Um atendimento deve ser adequado desde o momento em que a pessoa adentra ao serviço, dessa maneira, o acolhimento é algo essencial e indispensável para que haja continuidade do cuidado. Por isso, faz-se necessário problematizar, junto aos profissionais das unidades de saúde, desde a portaria até o consultório, as consequências de atitudes, comportamentos e falas cisheteronormativas para a saúde dos homens trans. Isso pode ser feito através da realização de campanhas de caráter permanente de divulgação do direito ao atendimento livre de discriminação e ao uso do nome social, além da discussão da importância do acesso ao SUS a partir da sua principal porta de entrada.

Pode-se afirmar, portanto, que ainda existe um grande caminho a ser percorrido. A Enfermagem e os demais profissionais de saúde devem juntos auxiliar na concretização do Sistema Único de Saúde preconizado na Constituição Brasileira, no que diz respeito ao acesso aos serviços de saúde para os homens transexuais, principalmente para que o acesso siga um fluxo de atendimento entre os níveis de atenção que não sature o sistema, e mantendo a continuidade do cuidado. Além de objetivar saúde, como um conceito amplo, o qual culminará num bem-estar biopsicossocial.

\section{Referências}

Ahmad, A. F., Dantas, B. R. S. S., Fraga, F. A., Meneses, A. dos S., Ribeiro, C. R., \& Lemos, A. (2020). As expectativas dos homens trans diante da hormonização cruzada: contribuições da enfermagem no cuidado em saúde. Research, Society and Development, 9(11). https://doi.org/10.33448/rsdv9i11.9970

Almeida, G. (2012). 'Homens trans': novos matizes na aquarela das masculinidades? Estudos Feministas, 20(2), 513-523. https://doi.org/10.1590/S0104026 X2012000200012.

Arán, M., \& Murta, D. (2009). Do diagnóstico de Transtorno de Identidade de gênero às redescrições da experiência da transexualidade: uma reflexão sobre gênero, tecnologia e saúde. Physis: Revista de Saúde Coletiva, 19(1), 15-41. https://www.scielo.br/pdf/physis/v19n1/v19n1a03.pdf.

Arán, M., Murta, D., \& Lionço, T. (2009). Transexualidade e Saúde Pública no Brasil. Revista Ciência \& Saúde Coletiva, 14(4), 1141-1149. http://dx.doi.org/10.1590/S1413-81232009000400020 
Bento, B. (2008). O que é transexualidade. Brasiliense.

Botelho, L. L. R., Cunha, C. C. A., \& Macedo, M. (2011). O Método da Revisão Integrativa nos Estudos Organizacionais. Revista Eletrônica Gestão e Sociedade, 5(11), 121-136. https://www.gestaoesociedade.org/gestaoesociedade/article/view/1220/906.

Brasil. Ministério da Saúde (2014). Ministério da Saúde orienta sobre o preenchimento do nome social no Cartão SUS. Blog da Saúde. http://www.blog.saude.gov.br/index.php/geral/34540-ministerio-da-saude-orienta-sobre-o-preenchimento-do-nome-social-no-cartao-sus

Brasil. Ministério da Saúde (2008a). Portaria no 457, de 19 de agosto de 2008. Aprova a Regulamentação do Processo Transexualizador no âmbito do Sistema Único de saúde (SUS). http://bvsms.saude.gov.br/bvs/saudelegis/sas/2008/prt0457_19_08_2008.html

Brasil. Ministério da Saúde (2008b). Portaria $\mathrm{n}^{\circ}$ 1.707, de 18 de agosto de 2008. Institui, no âmbito do Sistema Único de Saúde (SUS), o Processo Transexualizador, a ser implantado nas unidades federadas, respeitadas as competências das três esferas de gestão. http://bvsms.saude.gov.br/bvs/saudelegis/gm/2008/prt1707_18_08_2008.html

Brasil. Ministério da Saúde (2013a). Portaria nº 2803, de 19 de novembro de 2013. Redefine e amplia o Processo Transexualizador no Sistema Único de Saúde (SUS). http://bvsms.saude.gov.br/bvs/saudelegis/gm/2013/prt2803_19_11_2013.html

Brasil. Ministério da Saúde (2013b). Política Nacional de Saúde Integral de Lésbicas, Gays, Bissexuais, Travestis e Transexuais. https://bvsms.saude.gov.br/bvs/publicacoes/politica_nacional_saude_lesbicas_gays.pdf

Brasil. Ministério da Saúde (2016). Cartilha Cuidar Bem da Saúde de Cada Um. Atenção Integral à Saúde da População Trans. Conteúdo para Profissionais de Saúde/Trabalhadores do SUS. http://www.saude.gov.br/images/pdf/2016/fevereiro/18/CARTILHA-Equidade-10x15cm.pdf

Braz, C. (2019). Vidas que esperam? Itinerários do acesso a serviços de saúde para homens trans no Brasil e na Argentina. Cadernos de Saúde Pública, 35(4). https://doi.org/10.1590/0102-311x00110518

Carrara, S., Hernandez, J. de G., Uziel, A. P., Conceição, G. M. S. da, Panjo, H., Baldanzi, A. C. de O., Queiroz, J. P., D'Angelo, L. B., Balthazar, A. M. S. e, Junior, A. L. da S., \& Giami, A. (2019). Body construction and health itineraries: a survey among travestis and trans people in Rio de Janeiro, Brazil. Cadernos de Saúde Pública, 35(4). https://doi.org/10.1590/0102-311x00110618

Coelho, M. O., \& Jorge, M. S. B. (2009). Tecnologia das relações como dispositivo do atendimento humanizado na atenção básica à saúdena perspectiva do acesso, do acolhimento e do vínculo. Ciência \& Saúde Coletiva, 14, 1523-1532. https://www.scielo.br/pdf/csc/v14s1/a26v14s1.pdf.

Geisler, A. R. R., Reis, V. L. M. dos, \& Sperlin, S. (2013). Cidadania e democracia sanitária: refletindo sobre o direito à saúde da população "trans" numa perspectiva de integralidade. Cadernos Ibero-Americanos de Direito Sanitário, 2(2), 242-251. https://doi.org/10.17566/ciads.v2i2.80.

Guimarães, N. P., Sotero, R. L., Cola, J. P., Antonio, S., \& Galavote, H. S. (2020). Avaliação da implementação da Política Nacional de Saúde Integral à população LGBT em um município da região Sudeste do Brasil. Reciis - Revista Eletrônica de Comunicação, Informação e Inovação em Saúde, 14(2), 372385. https://doi.org/10.29397/reciis.v14i2.1712.

Mello, L., Perilo, M., Braz, C. A. de, \& Pedrosa, C. (2011). Políticas de saúde para lésbicas, gays, bissexuais, travestis e transexuais no Brasil: em busca de universalidade, integralidade e equidade. Sexualidad, Salud y Sociedad, (9), 7-28. https://dx.doi.org/10.1590/S1984-64872011000400002.

Merhy, E. E. et al. (1997). Em busca de ferramentas analisadoras das tecnologias em saúde: a informação e o dia a dia de um serviço, interrogando e gerindo trabalho em saúde. In E. E. Merhy, R. Onocko (Org.). Agir em saúde: um desafio para o público. Hucitec.

Moscheta, M. dos S., \& Santos, M. A. dos. (2010). Inclusão e o desafio de criar formas de investigação colaborativas: um relato de experiência. Saúde e Transformação Social, 1(1), 154-159. https://www.researchgate.net/publication/277867757_Inclusao_e_o_desafio_de_criar_formas_de_i nvestigacao_colaborativas_-_um_relato_de_experiencia_Inclusion_and_the_challenge_to_create_colaborative_forms_of_investigation_an_experience_re port\#read.

Oliveira, F. (2014). Transexualidade ou "Transexualismo"? A construção da cidadania trans. Direito e Diversidade Sexual. https://flaviotartuce.jusbrasil.com.br/artigos/144342466/transexualidade-ou-transexualismo.

Oliveira, G. S., Nogueira, J. de A., Costa, G. P. O., Silva, F. V. da, \& Almeida, S. A. de. (2018). Acesso de lésbicas, gays, bissexuais e travestis/transexuais às Unidades Básicas de Saúde da Família. Revista Rene, 19. https://www.redalyc.org/jatsRepo/3240/324054783018/html/index.html.

Oliveira, G. S., Nogueira, J. de A., Costa, G. P. O., Medeiros, R. L. S. F. M. de, Oliveira, T. de, \& Almeida, S. A. de. (2018). Serviços de saúde para lésbicas, gays, bissexuais e travestis/transexuais. Revista de Enfermagem UFPE online, 12(10), 2598-2609. https://doi.org/10.5205/1981-8963-v12i10a237014p25982609-2018.

Paulino, D. B., Rasera, E. F., \& Teixeira, F. do B. (2019). Discursos sobre o cuidado em saúde de Lésbicas, Gays, Bissexuais, Travestis, Transexuais (LGBT) entre médicas(os) da Estratégia Saúde da Família. Interface - comunicação, saúde, educação, 23. https://doi.org/10.1590/interface.180279.

Pereira, L. B. de C., \& Chazan, A. C. S. (2019). O Acesso das Pessoas Transexuais e Travestis à Atenção Primária à Saúde: uma revisão integrativa. Revista Brasileira de Medicina de Família e Comunidade, 14(41). https://doi.org/10.5712/rbmfc14(41)1795.

Popadiuk, G. S. P., Oliveira, D. C., \& Signorelli, M. C. (2017). A Política Nacional de Saúde Integral de Lésbicas, Gays, Bissexuais e Transgêneros (LGBT) e o acesso ao Processo Transexualizador no Sistema Único de Saúde (SUS): avanços e desafios. Ciência \& Saúde Coletiva, 22(5), 1509-1520. https://dx.doi.org/10.1590/1413-81232017225.32782016.

Rocon, P. C, Rodrigues, A., Zamboni, J., \& Pedrini, M. D. (2016). Dificuldades vividas por pessoas trans no acesso ao Sistema Único de Saúde. Ciência \& Saúde Coletiva, 21(8), 2517-2526. https://doi.org/10.1590/1413-81232015218.14362015. 
Research, Society and Development, v. 10, n. 1, e2110212018, 2021

(CC BY 4.0) | ISSN 2525-3409 | DOI: http://dx.doi.org/10.33448/rsd-v10i1.12018

Solka, A. C., \& Antoni, C de. (2020). Homens trans: da invisibilidade à rede de atenção em saúde. Revista Saúde e Desenvolvimento Humano, 8(1), 07-16. http://dx.doi.org/10.18316/sdh.v8i1.4895.

Souza, D., \& Iriart, J. (2018). "Viver dignamente": necessidades e demandas de saúde de homens trans em Salvador, Bahia, Brasil. Cadernos de Saúde Pública, 34(10). https://doi.org/10.1590/0102-311x00036318.

Souza, M. T. de, Silva, M. D. da, \& Carvalho, R. de. (2010). Revisão integrativa: o que é e como fazer. Einstein, 8(1), 102-106. https://dx.doi.org/10.1590/s1679-45082010rw1134.

Vieira, E. S., Pereira, C. A. S. R., Dutra, C. V., \& Cavalcanti, C. S. (2019). Psicologia e Políticas de Saúde da População Trans: Encruzilhadas, Disputas e Porosidades. Psicologia: Ciência e Profissão, 39, 161- 173. https://dx.doi.org/10.1590/1982-3703003228504. 